\title{
Prevalence, awareness, treatment and control of hypertension in a nigerian population
}

\author{
Obinna Ikechukwu Ekwunife*, Patrick Obinna Udeogaranya, Izuchukwu Loveth Nwatu
}

Department of Clinical Pharmacy and Pharmacy Management, University of Nigeria Nsukka; Department of Pharmacy, Enugu State Teaching Hospital Enugu State, Nigeria; ${ }^{*}$ Corresponding Author: obinna.ekwunife@unn.edu.ng

Received 19 January 2010; revised 24 March 2010; accepted 26 March 2010.

\begin{abstract}
Hypertension is a major public health problem. Due to paucity of data, the burden of hypertension in Nigeria might be underestimated. Estimating the prevalence of hypertension in populations of Nigeria would be useful in efforts to control hypertension and prevent its consequences. This survey aimed to assess the prevalence, detection, treatment and control of hypertension in Nsukka, a city located in SouthEastern Nigeria. Hypertension prevalence, awareness, treatment, and control (outcomes) were examined in 756 adult participants (364 men and 392 women) aged 18 years and above. Blood pressure (BP) of the participants was measured and they also answered a detailed questionnaire. Hypertension was defined as BP $\geq 140$ for systolic BP and or $\geq 90 \mathrm{~mm} \mathrm{Hg}$ for diastolic BP or being on antihypertensive therapy. Prevalence of hypertension was $21.1 \%$. Men had higher prevalence of high BP compared to women. Systolic and diastolic BP increased with age in both men and women. Detection of high BP in participants with raised blood pressure was $40.3 \%$ and $24.7 \%$ for males and females respectively. Only $23.7 \%$ and $17.5 \%$ of males and females respectively with high BP were on antihypertensive treatment while $5.0 \%$ of males and $17.5 \%$ of females with hypertension were controlled. Prevalence of hypertension was comparable with other studies in Nigeria and Africa. The results showed a poor detection, treatment and control of hypertension. This underscores the need for comprehensive evaluation of the prevalence of hypertension and other cardiovascular diseases in Nigeria.
\end{abstract}

Keywords: Hypertension; Prevalence;

Epidemiology; Nsukka

\section{INTRODUCTION}

Hypertension is a major public health problem. Worldwide, prevalence estimates for hypertension is about 1 billion individuals [1]. It causes about 7.1 million deaths per year [2] and $4.5 \%$ of the disease burden which translates to 64 million disability adjusted life years (DALYs) [3]. The relationship between blood pressure (BP) and risk of cardiovascular diseases events is continuous, consistent, and independent of other risk factors. The higher the BP, the greater is the chance of heart attack, heart failure, stroke, and kidney diseases [4].

The burden of non-communicable diseases (NCDs) such as hypertension is increasing in epidemic proportions in Africa. According to the World Health Report 2001 , NCDs accounted for $22 \%$ of the total deaths in the region in the year 2000; cardiovascular diseases alone accounted for $9.2 \%$ of the total deaths, killing even more than malaria [2]. Major target-organ complications of hypertension, such as left ventricular hypertrophy [5], diastolic dysfunction [6], congestive heart failure [7], ischemic heart disease [8], stroke [9], and renal failure [10] have been established by various researchers in $\mathrm{Ni}-$ geria.

Reducing the prevalence of hypertension would decrease mortality and disability in middle-aged and older persons and lead to a better quality of life. Reduction of hypertension prevalence could be achieved through risk factor prevention programmes as well as using low-cost management. However, in most countries of the African region, implementation of these approaches and programmes is hampered by dearth of data on the prevalence and control levels of hypertension. Scarcity of data is sometimes understood as non-existence of the problem [3]. There is paucity of hypertension prevalence in many populations of Nigeria. Thus, burden of hypertension in these populations might be underestimated and might leave the illness undiagnosed and untreated. Uncontrolled hypertension clearly places a substantial strain on health care delivery system. Estimating the preva- 
lence of hypertension in populations of Nigeria would be useful in efforts to control hypertension and other NCDs. This survey aimed to assess the prevalence, detection, treatment and control of hypertension in Nsukka, a city located in South-Eastern Nigeria.

\section{METHOD}

\subsection{Study Design and Population}

This is a household survey with the objective of assessing prevalence, awareness and control of hypertension in Nsukka. Nsukka is a town located in South-Eastern Nigeria and has an estimated population of 117,086. Christianity is the main religion while farming, transportation and trading are the major commercial activities. The most prominent feature in Nsukka is the University of Nigeria Nsukka, which attracts people of different ethnic and linguistic group to the area. There are 19 public health facilities and over 20 private health facilities in Nsukka.

\subsection{Ethical Consideration}

All procedures were carried out according to a study protocol approved by the Local Ethics Committee of University of Nigeria Teaching Hospital Enugu. Objectives and nature of the study were explained to people that agreed to participate. Informed consent was orally obtained. The information about participant's identity was not included with the other data and only the principal investigator had access to this information. No reference to the participant's identity was made at any stage during data analysis.

\subsection{Sampling and Sample Size Calculation}

A mixture of cluster and systematic random technique was employed. Nsukka was grouped into 16 clusters based on geographical locations as established by a map designed by Nsukka Graduates Association. Six sections or clusters were randomly selected from the sixteen clusters using a random sampling technique. In each section, the first house in each street was identified, followed by systematic sampling of the next three houses. Using "Statcalc" function of EPI INFO (Version 6, Centre for Disease Control, USA), it was determined that a sample size of 400 was adequate to detect prevalence of hypertension of $10 \%$ to $40 \%$ with $5 \%$ precision and $95 \%$ confidence. However, a total of 800 persons were met in the exercise after covering the selected clusters.

\subsection{BP Measurement and Interview Procedure}

The data collection tool was a questionnaire. The survey was carried out from April to August of 2009. Partici- pants that were included in the study were those from 18 years and above in each household identified. Those who took caffeine, smoked or did an exercise prior to the interview were excluded from the study. Participants were interviewed and blood pressure was measured at home. Data obtained were marital status, age, gender, educational status, estimated income per month, family history of hypertension, and co-morbidities. The interview was in English or in Igbo (the local dialect) for participants that could not understand English. Blood pressure was measured twice by the trained final year pharmacy students using mercury sphygmomanometers and stethoscopes (Kris-Alloy®, Wuxi Medical Instrument Factory, Wuxi City Jiangsu, China). Blood pressure was measured after they were in resting state for 10 minutes and in sitting position in the right arm place at the level of the heart. An appropriate-sized cuff (cuff bladder encircling at least $80 \%$ of the arm) was used to ensure accuracy [4]. High blood pressure was defined using the $\mathrm{WHO} / \mathrm{ISH}$ criteria of $\mathrm{SBP} \geq 140 \mathrm{mmHg}$ and/or $\mathrm{DBP} \geq 90 \mathrm{mmHg}$ [11]. Prevalence of high BP was calculated as percentage of participants with SBP and DBP above WHO/ISH criteria, those that were known hypertensive and those on hypertension medication (s). Hypertension detection was defined as any prior diagnosis of hypertension made by a health professional among the population defined as having hypertension. Treatment of hypertension was defined as use of recognized antihypertensive medication among the population defined as having hypertension, whereas control of hypertension was defined as blood pressure of $<140 / 90 \mathrm{mmHg}$ among the population defined as having hypertension.

\subsection{Data Analysis}

Mean levels of BP were reported by gender (male versus female) and age. Gender difference in blood pressure was conducted using 2-sample t-test while gender differences in detection, treatment and control rate was assessed using $\chi^{2}$ test. All data analyses were conducted using SPSS 13.0 (Chicago, IL) software. Data were double checked by a staff of Clinical Pharmacy department, University of Nigeria Nsukka for consistency. A twotailed significance level of 0.05 was used.

\section{RESULTS}

A total of 800 participants were encountered in their homes but only 756 participants agreed to participate in the study (94.5\% response rate). Majority of those that declined to participate were afraid to be diagnosed of hypertension and would not want their blood pressure measured. The rest did not want to participate because of time the exercise will take. Three hundred and sixty four 
(48.1\%) were males while three hundred and ninety-two $(51.9 \%)$ were females. Majority of the participants (about 60\%) were married while the rest were single. Only a few of the participant $(<1 \%)$ were divorced. About $26 \%$ of the participants had a tertiary degree, $58 \%$ had up to secondary school training while $3 \%$ had no formal education. One half of the study population earned less than $\$ 100$ in a month and men significantly earned more than women (T-test, $\mathrm{p}<0.001$ ). Details of the demographic characteristics of the study population are presented in Table $\mathbf{1}$.

Table 2 shows the details of clinical characteristics of the study population. Among the participants, $23.5 \%$ reported that they have a family history of hypertension. Mean systolic blood pressure in the study population was $129.8 \pm 27.4 \mathrm{mmHg}$ and mean diastolic blood pressure $85.1 \pm 9.9 \mathrm{mmHg}$. Males had a significantly higher SBP compared to females $-133.3 \pm 14.3 \mathrm{mmHg}$ vs 125.0 $\pm 14.6 \mathrm{mmHg}$ respectively (T-test, $\mathrm{p}<0.001$ ). DBP was also significantly higher in males than in females -87.1 $\pm 9.3 \mathrm{mmHg}$ vs $83.2 \pm 10.2 \mathrm{mmHg}$ respectively (T-test, $\mathrm{p}<0.001)$. Prevalence of high blood pressure was $21.1 \%$. Systolic and diastolic BP increased with age as shown in Figure 1.

Detection of high BP in participants with raised blood

Table 1. Demographic characteristics of the study population $(\mathrm{n}=756)$.

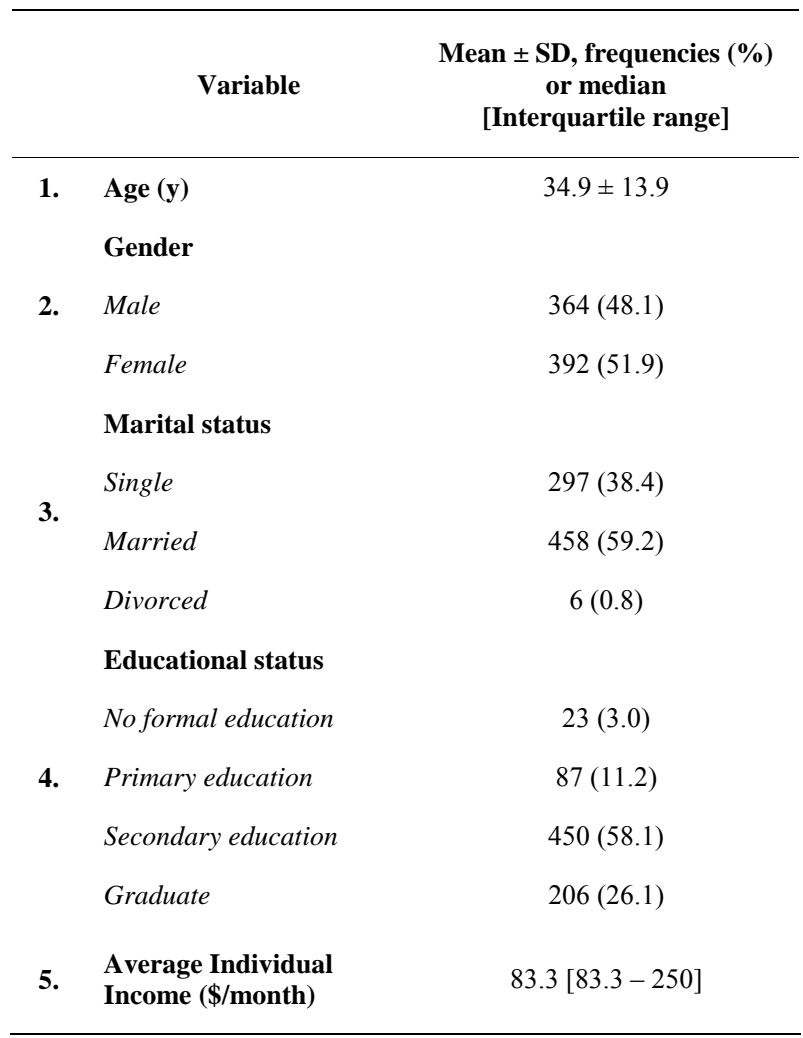

Table 2. Clinical characteristics of the study population.

\begin{tabular}{clc}
\hline & \multicolumn{1}{c}{ Variable } & $\begin{array}{c}\text { Mean } \pm \text { SD or } \\
\text { percentages (\%) }\end{array}$ \\
\hline 1. & Family history of hypertension & 23.5 \\
2. & Systolic blood pressure $(\mathrm{mm} \mathrm{Hg})$ & $129.8 \pm 27.4$ \\
3. & Diastolic blood pressure $(\mathrm{mm} \mathrm{Hg})$ & $85.1 \pm 9.9$ \\
4. & Prevalence of BP & 21.1 \\
\hline
\end{tabular}

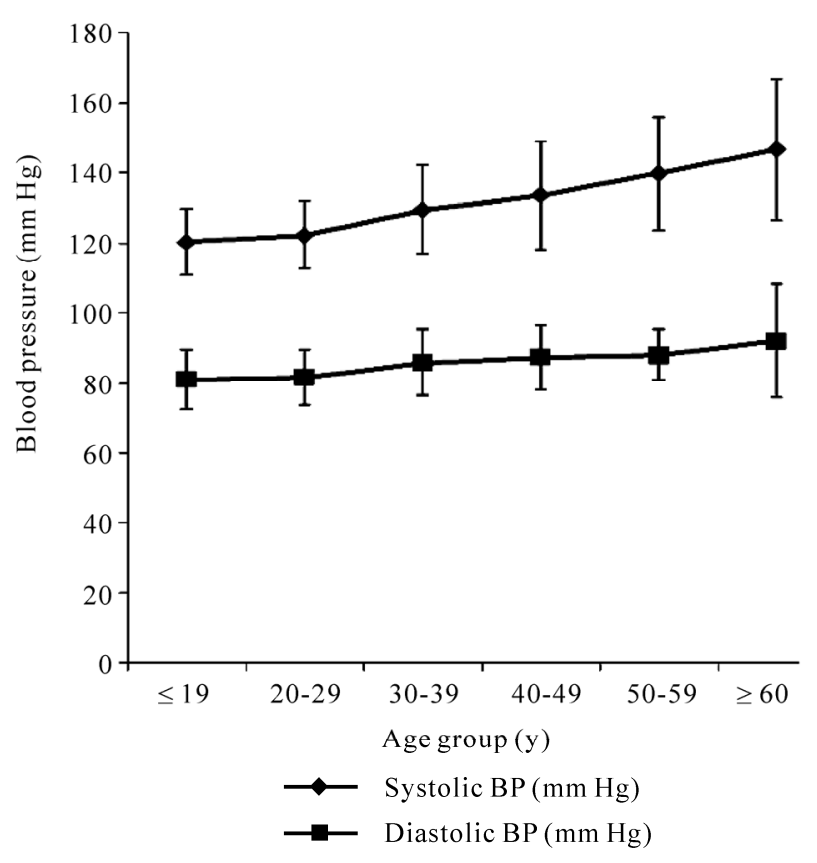

Figure 1. Systolic and diastolic BP by age group in Nsukka urban, Nigeria. Results are shown as mean and standard deviation.

pressure was significantly higher in males $(40.3 \%)$ compared to females $(24.7 \%)\left(\chi^{2}(1)=4.2, p=0.041\right)$. Overall detection rate was $30 \%$. Percentage of participants with high BP treated were $23.7 \%$ for males and $17.5 \%$ for males and females respectively. There was no significantly difference in treatment rate between men and women $\left(\chi^{2}(1)=0.83, p=0.36\right)$. On the total, $21 \%$ of participants with high BP take medications. On control rate, $17.5 \%$ of the women were controlled while $5.0 \%$ of the men were controlled. There was significant gender difference in control rate $\left(\chi^{2}(1)=6.73, \mathrm{p}=0.01\right)$. Overall control rate of BP amongst hypertensive was $9 \%$ in the study population.

\section{DISCUSSION}

This study presents the prevalence estimate of hypertension in Nsukka, an urban town in South-Eastern Nigeria. 
Table 3. Blood pressure by age group and gender.

\begin{tabular}{|c|c|c|c|c|c|c|}
\hline \multirow{3}{*}{$\begin{array}{c}\text { Age group (y) } \\
\leq 19\end{array}$} & \multirow{3}{*}{$\begin{array}{l}\mathbf{n} \\
28\end{array}$} & Systolic BP (mm Hg) & Diastolic BP (mm Hg) & \multirow{3}{*}{$\begin{array}{l}\mathbf{n} \\
31\end{array}$} & \multirow{2}{*}{\multicolumn{2}{|c|}{$\begin{array}{c}\text { Systolic BP }(\mathbf{m m ~ H g}) \quad \text { Diastolic BP }(\mathbf{m m ~ H g} \\
\text { Women }(\mathrm{n}=392)\end{array}$}} \\
\hline & & \multicolumn{2}{|c|}{ Men $(n=364)$} & & & \\
\hline & & $123 \pm 10$ & $81 \pm 8$ & & $118 \pm 8$ & $82 \pm 8$ \\
\hline $20-29$ & 106 & $127 \pm 9$ & $85 \pm 8$ & 162 & $119 \pm 9$ & $80 \pm 8$ \\
\hline $30-39$ & 75 & $132 \pm 12$ & $88 \pm 9$ & 109 & $127 \pm 13$ & $85 \pm 9$ \\
\hline $40-49$ & 85 & $136 \pm 15$ & $88 \pm 8$ & 48 & $128 \pm 16$ & $86 \pm 12$ \\
\hline $50-59$ & 36 & $143 \pm 15$ & $89 \pm 6$ & 18 & $136 \pm 17$ & $88 \pm 9$ \\
\hline$\geq 60$ & 34 & $147 \pm 17$ & $94 \pm 14$ & 24 & $145 \pm 25$ & $90 \pm 19$ \\
\hline
\end{tabular}

Results are presented mean \pm standard deviation

Blood pressure showed a consistent increase with age in both men and women. The survey showed that only $30 \%$ of persons with raised blood pressure were detected, $21 \%$ were detected, while $9 \%$ were controlled.

Similar prevalence estimate have been documented in the literature. In South-Eastern Nigeria, prevalence of hypertension in a university community was as much as $21 \%$ [12]. Arterial hypertension was found in $25 \%$ of examined motor bike riders in Benin City, Nigeria [13]. It has been speculated that about 20\%-25\% Nigerian adults could be classed as hypertensive [14].

The consistent increase of blood pressure with age in both men and women is a known occurrence and has been reported elsewhere in Africa [15]. A recent study in Nigeria (Kogi State) showed that blood pressures increased with age and body mass index [16]. The agerelated rise in systolic blood pressure is primarily responsible for an increase in both incidence and prevalence of hypertension with age [17]. It has been stated that the prevalence of hypertension increases with advancing age to the point where more than half of people aged 60 to 69 years old and approximately three-quarters of those aged 70 years and older are affected [1]. Though blood pressure increased with age, men had a significantly higher blood pressure than women in all the age groups.

The survey showed that only $30 \%$ of persons with raised blood pressure were detected, $21 \%$ were treated, while $9 \%$ were controlled. In general, our results showed a comparable level of detection, treatment and control of hypertension with those that have been reported in other surveys in Africa. For example in Ghana, it was reported that only $34 \%$ were aware that their blood pressure was high and $22.2 \%$ were taking antihypertensive medication, but only $6.2 \%$ had optimal blood pressure control [18]. Although a recent survey in Nigeria by Omuemu et al., reported a lower detection rate of $18.5 \%$ compared to
$30 \%$ obtained in this survey, treatment and control rates in both surveys were comparable [19].

This study strengthens the fact that in sub-Saharan Africa, level of detection, treatment and control are still far less than results obtained in developed countries [20]. This poor level of detection, treatment and control has been attributed to scarce resources and inadequate healthcare provision $[21,22]$. The poor level of detection, treatment and control of hypertension is a cause of concern. As hypertension is an important cardiovascular risk factor, many undetected hypertensive patients have a high risk of suffering from cardiovascular disease consequences such as myocardial infarction and stroke. As was stated earlier, the burden of hypertension might be underestimated in Nigeria.

This study had some limitations. Stratified sampling technique would have been the best sampling method which will ensure the generalizability of the prevalence estimate. Also, since the blood pressure of the entire residents' ( $\geq 18$ years) in the identified houses was measured, clustering effect could have resulted diluting the randomness of the sampling.

\section{CONCLUSIONS}

Prevalence of hypertension was comparable with other studies in Nigeria and Africa. Our results also showed a poor detection, treatment and control of hypertension than has been reported in other surveys in Africa. This underscores the need for comprehensive evaluation of prevalence of hypertension and other cardiovascular diseases in Nigeria. Information from this assessment could demonstrate the need to urgently address this emerging disease. It is also imperative to design costeffective strategies which could be implemented to improve detection, adherence and control of hypertension in Nigeria. 


\section{ACKNOWLEDGEMENTS}

The authors wish to acknowledge the following final year pharmacy students that took part in the field study: Ejike Onah, Ifeanyi Aduaka, and Theresa Money.

\section{REFERENCES}

[1] Burt, V.L., Whelton, P., Roccella, E.J., Brown, C., Cutler, J.A., Higgins, M., et al. (1995) Prevalence of hypertension in the US adult population. Results from the Third National Health and Nutrition Examination Survey. 1988-1991. Hypertension, 25(3), 305-313.

[2] World Health Report (2002) Reducing risks, promoting healthy life. World Health Organization, Geneva, Switzerland. http://www.who.int/whr/2002/en/whr02 en. pdf

[3] World Health Organisation. (2008) Prospects of Research on non-communicable diseases in the African sub-region. http://www.afro.who.int/dpm/rpc/publications/ncdwok.pdf

[4] Chobanian, A.V., Bakris, J.L., Black, H.R., Cushman, W.C., Green, L.A., Izzo, J.L., et al. (2003) Seventh report of the Joint National Committee on Prevention, Detection, Evaluation, and Treatment of High Blood Pressure: The JNC 7 report. The Journal of the American Medical Association, 289(9), 2560.

[5] Opadijo, O.G., Omotoso, A.B.O., Akande, A.A. (2003) Relation of electrocardiographic left ventricular hypertrophy to blood pressure, body mass index, serum lipids and blood sugar levels in adult Nigerians. African Journal of Medicine and Medical Sciences, 32(4), 395-399.

[6] Ike, S.O. and Onwubere, B.J. (2003) The relationship between diastolic dysfunction and level of blood pressure in Blacks. Ethnicity \& disease, 13(4), 463-469.

[7] Falase, A.O., Ayeni, O., Sekoni, G.A. and Odia, O.J. (1983) Heart failure in Nigerian hypertensives. African Journal of Medicine and Medical Sciences, 12(1), 7-15.

[8] Falase, A.O., Cole, T.O. and Osuntokun, B.O. (1974) Myocardial infarction in Nigerians. Tropical and Geographical Medicine, 25(2), 147-150.

[9] Osuntokun, B.O., Bademosi, O., Akinkugbe, O.O. and Oyediran, A.B. (1979) Carlisle R. Incidence of stroke in an African city: Results from the stroke registry at Ibadan, Nigeria, 1973-1975. Stroke, 10(2), 205-207.

[10] Akinkugbe, O.O. (1992) Tropical nephropathy-an overview. African Journal of Medicine and Medical Sciences, 21(1), 3-7.

[11] WHO/ISH (2003) World Health Organisation (WHO)/ International Society of Hypertension (ISH) statement on management of hypertension. Journal of Hypertension, 21, 1983-1992.

[12] Erhun, W.O., Olayiwola, G., Agbani, E.O. and Omotoso, N.S. (2005) Prevalence of Hypertension in a University Community in South West Nigeria. African Journal of Microbiology Research, 8(1), 15-19.

[13] Ibhazehiebo, K., Iyawe, V.I. and Ighoroje, I.D. (2007) Epidemiologic Studies of the Prevalence of Arterial Hypertension among Commercial Motor Bike Riders in Benin City, Nigeria. Nigerian Journal of Health and Biomedical Sciences, 6(2), 26-29.

[14] Ogah, O.S. (2006) Hypertension in Sub-Saharan African Populations: The burden of Hypertension in Nigeria. Ethnic Disparities, 16(4), 765.

[15] Cappucio, F.P., Micah, F.B., Emmitt, L., Kerry, S.M., Antwi, S. and Martin-Peprah, R., et al. (2004) Prevalence, Detection, Management, and Control of Hypertension in Ashanti, West Africa. Hypertension, 43(5), 1017-1022.

[16] Ejike, C.E.C.C., Ugwu, C.E., Ezeanyika, L.U.S. and Olayemi, A.T. (2008) Blood pressure patterns in relation to geographic area of residence: A cross-sectional study of adolescent in Kogi State, Nigeria. BMC Public Health, 8(1), 411.

[17] Franklin, S.S., Gustin, W., Wong, N.D., Larson, M.G., Weber, M.A. and Kannel, W.B., et al. (1997) Hemodynamic patterns of age-related changes in blood pressure. The Framingham Heart Study. Circulation, 96(1), 308315.

[18] Cooper, R., Rotimi, C., Ataman, S., McGee, D., Osotmehin, B., Kadiri, S., Muna, W., Kingue, S., Fraser, H., Forrester, T., Bennett, F. and Wilks, R. (1997) The prevalence of hypertension in seven populations of West African origin. American Journal of Public Health, 87(2), 160-168.

[19] Omuemu, V.O., Okojie, O.H. and Omuemu, C.E. (2007) Awareness of high blood pressure status, treatment and control in a rural community in Edo State. Nigerian Journal of Clinical Practice, 10(3), 208-212.

[20] Wyatt, S.B., Akylbekora, E.L., Wofford, M.R., Coady, S.A., Walker, E.R. and Andrew, M.E., et al. (2008) Prevalence, Awareness, Treatment, and Control of Hypertension in the Jakson Heart Study. Hypertension, 51(3), 650-656.

[21] Pobee, J.O.M. (1993) Community-based high blood pressure programs in sub-Saharan Africa. Ethnic Disparities, (Suppl 3), 38-45.

[22] Seedat, Y.K. and Seedat, M.A. (1982) An inter-racial study of the prevalence of hypertension in an urban South African population. Transactions of the Royal Society of Tropical Medicine and Hygiene, 76(1), 62-71. 